\section{Out of the frying pan into the fire- the never forgiving complex congenital heart: a case of liquefied splenic infarct post-electrophysiology ablation}

A 36-year-old man born with pulmonary atresia intact ventricular septum, atrial septal defect and Ebstein anomaly with hypoplastic right heart (figure 1 and online supplementary video). Waterson shunt had been performed in childhood, but over a period of time it had occluded with pulmonary circulation being dependent on bronchopulmonary collaterals. He is on targeted therapy for pulmonary hypertension. He was symptomatic with intermittent focal atrial tachycardia, despite amiodarone therapy. Coumarin therapy was avoided due to risk of massive haemoptysis. At electrophysiology, he had an atrial flutter

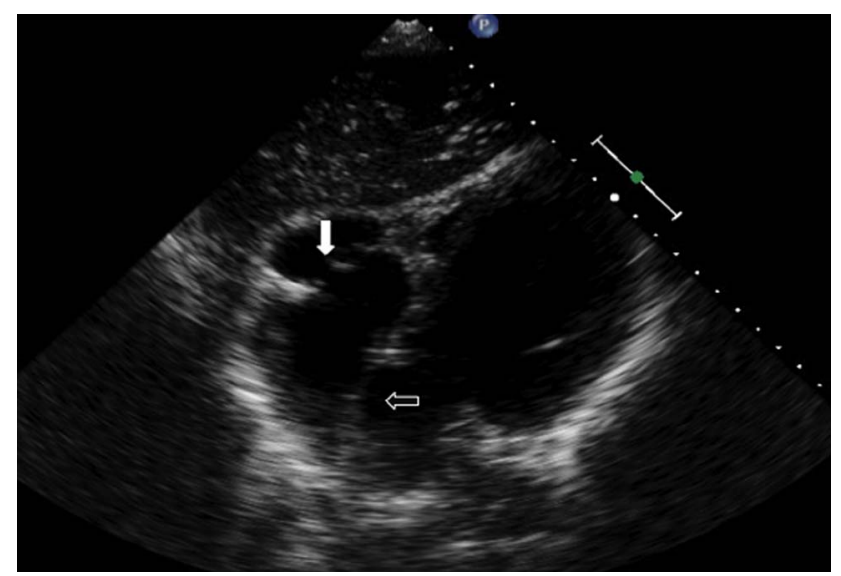

Figure 1 Subcostal echocardiographic view showing large atrial septal defect as indicated by the black arrow, with Ebstein-like tricuspid valve and hyperplasic right ventricle as indicated by the white arrow. circuit, which was resolved by cavotricuspid isthmus ablation. Postablation, he developed pleuritic left-sided chest and shoulder tip pain treated as lower respiratory tract infection. He continued to have significant pain with symptoms of sepsis. CT scan demonstrated number of splenic infarcts and a large splenic liquefied haematoma. Aspiration of the splenic haematoma showed altered blood. Diagnosis was of splenic infarcts secondary to embolisation at time of ablation, associated with subsequent infarct liquefaction with a splenic size of $16 \mathrm{~cm}$ (figure 2).

Splenic infarcts are not a recognised complication of rightsided catheter ablation-systemic emboli may occur in left atrial ablation. ${ }^{1}$ In cases with systemic to pulmonary shunts or septal defect, the substrate for systemic emboli is clearly present.

Splenic haematomas have been shown to resolve over time. Splenectomy may be an option, ${ }^{2}$ but in his case would be potentially fatal due to his pulmonary arterial hypertension, although liquefied haematomas do regress over time. As a major part of the spleen has liquefied, prophylaxis against pneumococcal infection is recommended in this patient with cyanotic congenital heart disease.

\section{Isma Rafiq, Danielle Deaville-Lees, Leisa J Freeman}

Department of Cardiology, Norfolk and Norwich University Hospital, Norwich, UK

Correspondence to Dr Isma Rafiq, Department of Cardiology, Norfolk and Norwich University Hospital, Colney lane, Norwich, Norfolk NR4 7UY, UK; ismach@doctors.org.uk

Contributors This patient has been under our care. Being the senior registrar, I have been thoroughly involved in the care and preparing the case for publication with the help of DD-L and LJF who is the designated consultant for the patient.

\section{Competing interests None.}

Provenance and peer review Not commissioned; internally peer reviewed.

- Additional material is available. To view please visit the journal online (http://dx. doi.org/10.1136/heartasia-2014-010548).

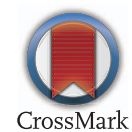

To cite Rafiq I, Deaville-Lees D, Freeman L. Heart Asia 2014;6:120.

Heart Asia 2014;6:120. doi:10.1136/heartasia-2014-010548

\section{REFERENCES}

1 Nores M, Phillips EH, Morgenstern L. The clinical spectrum of splenic infarction. Am Surg 1998;64:182-8.

2 Jaroch MT, Broughan TA, Hermann RE. The natural history of splenic infarction. Surgery 1986;100:743-50.
Figure 2 Sagittal and coronal MRI images showing large liquefied splenic infarct as indicated by the white arrow, led to increase in splenic size from 6 $\mathrm{cm}$ to $16 \mathrm{~cm}$.

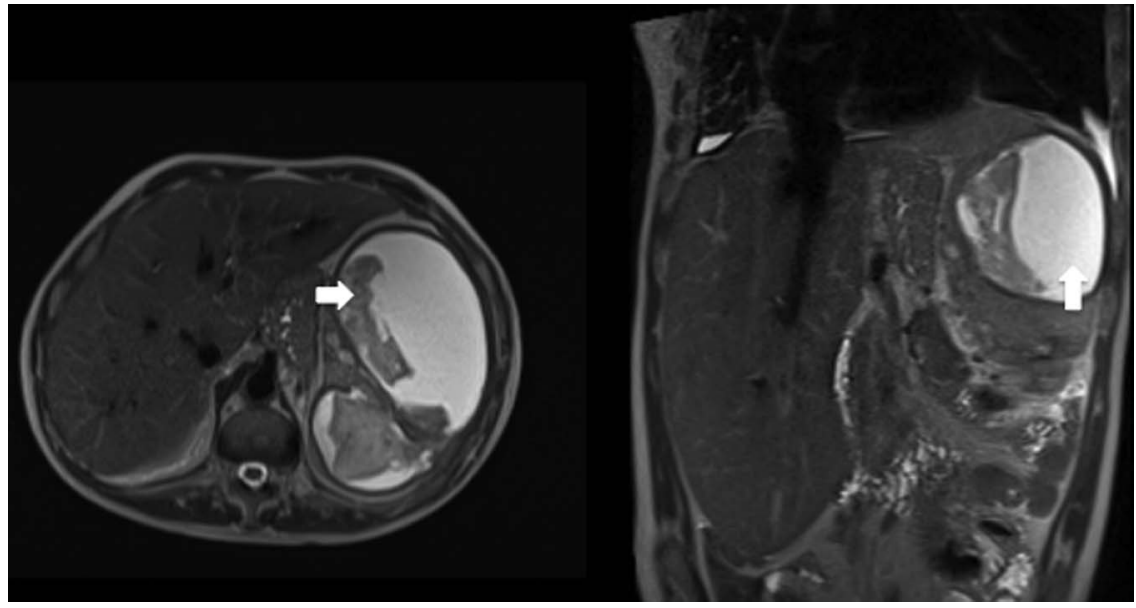

